\title{
Induced Changes in Phenolic Composition of Wines After Foliar Application of Eugenol and Guaiacol Solutions to Grapevines
}

\author{
Ana I Pardo-García ${ }^{1}$, Ana M Martínez-Gil ${ }^{1}$, Francisco Pardo ${ }^{2}$, Gonzalo L. Alonso ${ }^{1} \&$ M Rosario Salinas ${ }^{1}$ \\ ${ }^{1}$ Cátedra de Química Agrícola. E.T.S.I. Agrónomos. Universidad de Castilla-La Mancha. Avda. España s/n., \\ Albacete 02071, Spain \\ ${ }^{2}$ Bodega San Isidro (BSI), Carretera de Murcia s/n, Jumilla 30520, Murcia, Spain \\ Correspondence: M Rosario Salinas, Cátedra de Química Agrícola. E.T.S.I. Agrónomos. Universidad de \\ Castilla-La Mancha. Avda. España s/n., Albacete 02071, Spain. Tel: 34-967-599-310. Fax: 34-967-599-238. \\ E-mail: Rosario.Salinas@uclm.es
}

Received: July 12, 2013 Accepted: August 1, 2013 Online Published: August 15, 2013

doi:10.5539/jas.v5n9p179 URL: http://dx.doi.org/10.5539/jas.v5n9p179

\begin{abstract}
Due to the beneficial properties of polyphenols in wines and the effect of external factors on them, this work evaluates the effect of the foliar application of eugenol and guaiacol on grapevines on the phenolic composition of wines elaborated from such grapes. Three different treatments were carried out on cv. 'Monastrell' at veraison time: eugenol, guaiacol and eugenol + guaiacol. Several families of phenolic compounds were studied in wines at three different sampling times, including phenolic acids, stilbenes, flavanols, flavonols and anthocyanins, which were analysed by HPLC-DAD-MS. Eugenol treatment enhanced the concentration of the studied compounds, guaiacol produced changes in the compounds related to primary metabolism, such as sugar and acids, as well in some polyphenols, but when eugenol and guaiacol were applied altogether similar changes to eugenol alone were observed, such as an increase in the content of anthocyanins and stilbenes among other phenolic compounds. Results suggest that foliar applications of eugenol on Monastrell grapevines (alone or together with guaiacol) could be considered as an important stimulant for production of grape polyphenols, implicated in quality color, as well as in beneficial properties on human health.
\end{abstract}

Keywords: eugenol, guaiacol, grapevines, wines, polyphenols

\section{Introduction}

Phenolic compounds are secondary plant metabolites synthesized by the shikimic acid rute. They have an important contribution on wine characteristics, such as color, astringency and bitterness. The biosynthesis of phenolic compounds in grapes is regulated by genetic factors, as well as the environment, climatic conditions and agronomic strategies (Vilanova, Santalla, \& Masa, 2009). The presence and quantity of these compounds in wines depend on their content in grapes, but also the winemaking techniques and conservation conditions of the wines, since phenolic compounds are implicated in a variety of reactions in wines, such as enzymatic, polymerisation, copigmentation and precipitation reactions, which cause changes throughout the life of a wine. Color is one of the most important quality parameters of wines, being the anthocyanins (red pigments present in grapes) the main contributors to color in a red wine. There are different structures of anthocyanins and derived of them which have diverse stability against certain factors such as $\mathrm{pH}$, temperature, light or $\mathrm{SO}_{2}$. From the first steps of the winemaking process to the ageing of the wine, monomeric anthocyanins are implicated in different phenomena. They can interact with themselves, resulting in polymerization, thereby increasing their stability and as consequence, the stability of the wine color. Moreover, other phenolic compounds, such as phenolic acids, flavanols and flavonols can interact as copigments with anthocyanins to form more stable structures. Depending on the compound, their effect as copigment is different. Flavanols seem to be the less effective copigments compared with hydroxicinnamic acids and flavonols, which enhance the color of malvidin-3-glucoside in model wine solutions (Gómez-Míguez, González-Manzano, Escribano-Bailón, Heredia, \& Santos-Buelga, 2006), although their addition of them has variable effects depending on the grape cultivar (Schwarz, Picazo-Bacete, Winterhalter, \& Hermosín-Gutiérrez, 2005). Recently, González-Manzano, Dueñas, Rivas-Gonzalo, Escribano-Bailón, and Santos-Buelga (2009) reported that flavanols induced changes in the color, perceptible to 
human eye. So, the levels of these copigments are as important as the levels of anthocyanins in determining the color of red wine. The production of an effective copigmentation is also due to winemaking practices.

Some studies show how different foliar applications on grapevines can modify the concentration of these compounds in both grapes and wines; so, Carmona, Peñaranda, Carrascal, Zalacain, and Salinas (2001) carried out one of the first studies related to vegetal extracts applied to vineyard, showing a significant increase in the color of Bobal grapes; Parrado et al. (2007) showed that the application of an vegetable extract on cv. 'Tempranillo', using a drip system, can enhance the concentration of anthocyanins in grapes. Recently, it has been reported that abscisic acid treatments enhance the synthesis of anthocyanins and flavonols depending on the cultivar (Sandhu, Gray, Lu, \& Gu, 2011).

Other studies showed changes in the aroma composition of grapes and the wines produced after foliar application of an aqueous oak extract (Martínez-Gil et al., 2013; Martínez-Gil, Garde-Cerdán, Martínez, Alonso, \& Salinas, 2011; Martínez-Gil, Garde-Cerdán, Zalacain, Pardo-García, \& Salinas, 2012). Oak extract is composed by a diversity of compounds, such as polyphenols and volatiles, being eugenol and guaiacol among them. So, treatments with both of these compounds were studied, showing that eugenol and guaiacol solution applied to grapevines resulted in changes in the volatile composition of wines and not only produced a considerably higher concentration of free eugenol and guaiacol compounds, but also modified the concentrations of other volatiles (Martínez-Gil et al., 2012), suggesting that these compounds were assimilated by the plant and accumulated in grapes. It had been also demonstrated that exogenous eugenol and guaiacol affected the volatile composition of tomatoes (Pardo-García, Martínez-Gil, López-Córcoles, Zalacain, \& Salinas, 2012), which seemed to be modulated by the treatments. Guaiacol and eugenol were absorbed by tomato plants after the exposure to a surrounding atmosphere as well after foliar treatment; both of them increased their content and changed the content of other volatile compounds in the fruits. Such effect could be due to a stimulation on the volatile production mechanism.

Eugenol is a phenylpropanoid while guaiacol is a phenylpropanoid derived. Both compounds are also products of the secondary metabolism of the plants and they are present in grapes and wines. Phenylpropanoids are a large group of plant volatile compounds that play multiple roles in the structure, the plant protection against pathogens (Gang et al., 2001) and they have important effects on product qualities such as flavour and color (Dixon, Lamb, Masoud, Sewalt, \& Paiva, 1996). Due to the fact that plant phenylpropanoid pathway is responsible for the synthesis of a wide variety of secondary metabolic compounds, including lignins, salicylates, coumarins, hydroxycinnamic amides, flavonoid phytoalexins, pigments, and antioxidants (Dixon et al., 1996), it could be suggested that any modification in the concentration of any compound could change the content of their products. In addition, it is also known that eugenol is a phenylpropanoid involved in defense mechanisms of the plants, whereas other phenolic compounds are related to the quality of wines. However, there is scarce literature about guaiacol implication in this role in plants.

The above evidences suggest that exogenous eugenol and guaiacol solutions applied to the grapevines could affect the secondary metabolites content of grapes such as the phenolic compounds and, as a consequence, in the produced wines. So, the aim of this study was to examine how the foliar applications of exogenous eugenol and guaiacol solutions to grapevines affect to the content and evolution of the main phenolic compounds in wines, such as phenolic acids, stilbenes, flavanols, flavonols and anthocyanins.

\section{Materials and Methods}

\subsection{Chemicals and Standards}

Eugenol and guaiacol were purchased from Sigma-Aldrich (Steinheim, Germany), as well as the standards employed to identify and quantify phenolic compounds such as: $(+)$-catechin, caffeic acid, $p$-coumaric acid, (-)-epicatechin, ferulic acid, gallic acid, kaempferol, quercetin dihydrate, $t$-resveratrol, syringic acid and vanillic acid. Malvidin-3-O-glucoside (Mv-3-G), Quercetin-3-O-glucoside (Q-3-G) and Kaempferol-3-O-glucoside (K-3-G) standard were obtained from Extrasynthése (Geneay, France). HPLC-grade acetonitrile was purchased from Panreac (Barcelona, Spain).

\subsection{Grapevine Treatments}

Experiment was carried out during the year 2010 in the experimental plot of BSI winery ( Jumilla, Southwest of Spain), latitude $38^{\circ} 28^{\prime} \mathrm{N}$, longitude $1^{\circ} 18^{\prime} \mathrm{W}$. The plot covered an area of 1.09 ha and had a loam soil $(8.7 \mathrm{pH}$, $7.5 \%$ lime, $58.33 \mathrm{meq} / \mathrm{L}$ of sulfates and $1 \%$ of organic matter). 8-year-old grapevines (Vitis vinifera cv. 'Monastrell') were cultivated on a trellis system $(2.8 \times 1.5 \mathrm{~m})$, fitted with a drip irrigation system and subjected 
to the same pruning practices. Similar climatic conditions were observed during the last years, with an annual average temperature of $16^{\circ} \mathrm{C}$ (minimum of $-15^{\circ} \mathrm{C}$ in January and a maximum of $40{ }^{\circ} \mathrm{C}$ in August).

Treatments were carried out over plants located in an edaphologically homogeneous part of the plot, avoiding its edges. All plants were disposed in rows, using 10 of them for the experiment. Each treatment was carried out over 16 different plants selected among the rows, so that treated and untreated rows were alternated to avoid contamination. Moreover, 16 additional plants were selected as control. The treatments were carried out when the environmental temperature was below $20^{\circ} \mathrm{C}$, at approximately $8 \mathrm{o}^{\prime}$ clock in the morning. Each was applied at the $7^{\text {th }}$ day of veraison. Treatments consisted of different aqueous solutions of reference compounds namely: eugenol (E treatment), guaiacol ( $G$ treatment) and eugenol+guaiacol ( $E+G$ treatment) in a concentration of $0.6 \%$ $(\mathrm{v} / \mathrm{v})$. A total of $5 \mathrm{~L}$ of each solution was directly sprayed over leaves (each plant was treated with $300 \mathrm{~mL}$ of solution approximately). For all treatments, $0.05 \%$ (v/v) of adjuvant Fluvius (BASF, Germany) was added, since this is a superficial wetting agent typically used for treatments with foliar herbicides, constituted by an inert mixture of polymers. Due to the fact that guaiacol and eugenol are present in grapes and wines, the applied quantity of each compound was chosen according to Martínez-Gil et al. (2012) and Pardo-García et al. (2012).

\subsection{Winemaking}

Healthy grapes were harvested on September $9^{\text {th }}$, at their optimum maturation moment with the ${ }^{\circ}$ Baumé/titratable acidity $\left(\mathrm{g} \mathrm{L}^{-1}\right.$ tartaric acid) ratio between 2.3 and 2.5 . Grapes were processed by the red winemaking traditional method. Grapes of each treatment were crushed, destemed, divided and placed into two $30 \mathrm{~L}$ stainless steel tanks ( 2 wines from each treatment were obtained). $80 \mathrm{mg} / \mathrm{L}$ of sulphur dioxide were added to each tank. After that, 20 $\mathrm{g} \mathrm{hL}^{-1}$ of yeast, UCLM S377 strain (Springer Oenologie) were inoculated to carry out the alcoholic fermentation, which took placed at a temperature of $22 \pm 1{ }^{\circ} \mathrm{C}$. After 11 days of maceration-fermentation, skins were removed with a traditional vertical hand-press. Then, each wine was given back to its tank to complete the alcoholic fermentation. Malolactic fermentation was induced using $8 \mathrm{~g} \mathrm{hL}^{-1}$ of a commercial bacterium strain, Lall II-4 (Lallemand). The malolactic fermentation was carried out in $5 \mathrm{~L}$ tanks. Once this step finalized, the wines were bottled and stored for six month. Three wine sampling times were performed: at the end of the alcoholic fermentation (AF), the malolactic fermentation (MLF) and after six months of MLF. Wine samples were frozen at $-20{ }^{\circ} \mathrm{C}$ until analysis.

\subsection{Analyses}

\subsubsection{Eugenol and Guaiacol Determination by SBSE-GC-MS}

The wine volatile compounds were extracted by stir bar sorptive extraction (SBSE) according to Marín, Zalacain, De Miguel, Alonso, \& Salinas (2005) and were analysed by gas chromatography-mass spectrometry (GC-MS). The polydimethylsiloxane coated stir bar $(0.5 \mathrm{~mm}$ film thickness, $10 \mathrm{~mm}$ length, Twister, Gerstel, Mülheim and der Ruhr, Germany) was introduced into $25 \mathrm{~mL}$ of wine, to which $62.5 \mu \mathrm{L}$ of internal standards $\gamma$-hexalactone and 3-methyl-1-pentanol solution at $1 \mu \mathrm{L} \mathrm{mL}^{-1}$, both in absolute ethanol (Merck, Damstard, Germany) was added. All samples were stirred at $500 \mathrm{rpm}$ at room temperature for $60 \mathrm{~min}$. The stir bar was then removed from the sample, rinsed with distilled water and dried with a cellulose tissue, and later transferred into a thermal desorption tube for GC-MS analysis. Thermal desorption was performed on a TD with a PTV injector "Programmed-Temperature Vaporization" CIS-4 Gerstel installed on an Agilent 7890A GC- 5975C insert XL MDS (Agilent Technologies, Palo Alto, CA, USA). Volatile compounds were desorbed from the stir bar at the following conditions: oven temperature at $330^{\circ} \mathrm{C}$; desorption time, $4 \mathrm{~min}$; cold trap temperature, $-30^{\circ} \mathrm{C}$; helium inlet flow, $45 \mathrm{~mL} / \mathrm{min}$. The compounds were transferred into the gas chromatograph with a fused silica capillary column (BP21 stationary phase, $50 \mathrm{~m}$ length, $0.22 \mathrm{~mm}$ i.d., and $0.25 \mu \mathrm{m}$ film thickness; SGE, Ringwood, Australia). The chromatographic program was set at $40^{\circ} \mathrm{C}$ (held for $2 \mathrm{~min}$ ), raised to $150^{\circ} \mathrm{C}$ at $10^{\circ} \mathrm{C} / \mathrm{min}$ (held for $5 \mathrm{~min}$ ) and then raised to $230^{\circ} \mathrm{C}$ at $10^{\circ} \mathrm{C} / \mathrm{min}$ (held for $2 \mathrm{~min}$ ). The total time analysis was 28 minutes. For mass spectrometry analysis, electron impact mode (EI) at $70 \mathrm{eV}$ was used. The mass range varied from 35 to $500 \mathrm{u}$ and the detector temperature was $150^{\circ} \mathrm{C}$. The identification and quantification were carried out in the SCAN mode. The analysis of volatile compounds in each wine sample was done in duplicate, and as the fermentations were done also in duplicate, the results showed for these compounds were the mean of 4 analyses. The identity of peaks was assigned using the NIST library and confirmed by the retention time of standards. The $\mathrm{m} / z$ employed for quantification was $\mathbf{1 0 9}$ and 164 for guaiacol and eugenol respectively. The quantification was based on five-point calibration curves of respective standards (Aldrich, Steinheim, Germany) $\left(\mathrm{R}^{2}>0.97\right)$ in ethanol-water solutions ( $12 \% \mathrm{v} / \mathrm{v}, \mathrm{pH}=3.6,5 \mathrm{~g} \mathrm{~L}^{-1}$ tartaric acid). 


\subsubsection{Oenological Parameters}

The classical parameters of wines such as alcoholic degree $\left({ }^{\circ} \mathrm{A}\right), \mathrm{pH}$, total acidity and volatile acidity were analysed by an equipment based on infrared spectroscopy (FT-IR Multispec of TDI) for liquid samples analysis attending the methods established by ECC (1990).

\subsubsection{Phenolic Compounds Determination by HPLC-DAD-MS}

Table 1. Retention times (Rt), ionization mode (ESI/MS), molecular weight and molecular ion $(\mathrm{m} / \mathrm{z})$ used for identification of hydroxycinnamic ester acids, flavonols and anthocyanins by MM-ESI-MS detector

\begin{tabular}{|c|c|c|c|c|}
\hline Compound assignation & $\begin{array}{l}\text { HPLC, } \\
\operatorname{Rt}(\min )\end{array}$ & $\begin{array}{c}\text { ESI/MS } \\
\text { mode }\end{array}$ & $\begin{array}{c}\text { Molecular } \\
\text { weight }\end{array}$ & $\begin{array}{l}\text { Molecular } \\
\text { ion }(\mathrm{m} / \mathrm{z})\end{array}$ \\
\hline \multicolumn{5}{|l|}{ Hydroxycinnamic ester acids } \\
\hline$t$-caftaric acid & 11.34 & negative & 312 & 311 \\
\hline$t$-coutaric acid & 14.65 & negative & 296 & 295 \\
\hline \multicolumn{5}{|l|}{ Flavonols } \\
\hline Myricetin 3-O-galactoside & 18.20 & negative & 480 & 479 \\
\hline Myricetin 3-O-glucuronide $^{\text {a }}$ & 18.47 & negative & 494 & 493 \\
\hline Myricetin 3-O-glucoside a & 18.58 & negative & 480 & 479 \\
\hline Quercetin 3-O-galactoside & 23.15 & negative & 464 & 463 \\
\hline Quercetin 3-O-glucuronide $^{\mathrm{b}}$ & 24.05 & negative & 478 & 477 \\
\hline Quercetin 3-O-glucoside ${ }^{\mathrm{b}}$ & 24.11 & negative & 464 & 463 \\
\hline Laricitrin 3-O-glucoside/galactoside $^{1}$ & 24.57 & negative & 494 & 493 \\
\hline Kaempferol 3-O-glucoside & 28.71 & positive & 447 & 447 \\
\hline Syringetin 3-O-glucoside & 29.57 & negative & 508 & 507 \\
\hline Myricetin & 31.63 & negative & 318 & 317 \\
\hline Quercetine & 36.79 & negative & 302 & 301 \\
\hline Kaempferol & 38.71 & positive & 286 & 285 \\
\hline \multicolumn{5}{|l|}{ Anthocyanins } \\
\hline Delphinidin 3-O-glucoside & 11.79 & positive & 464 & 465 \\
\hline Cyanidin 3-O-glucoside & 13.64 & positive & 448 & 449 \\
\hline Petunidin 3-O-glucoside & 14.40 & positive & 478 & 479 \\
\hline Peonidin 3-O-glucoside & 16.10 & positive & 462 & 463 \\
\hline Malvidin 3-O-glucoside & 16.60 & positive & 492 & 493 \\
\hline Petunidin 3-O-(6-O-acetyl)-glucoside & 22.42 & positive & 520 & 521 \\
\hline Peonidin 3-O-(6-acetyl)-glucoside & 26.63 & positive & 504 & 505 \\
\hline Malvidin 3-O-(6-acetyl)-glucoside & 27.20 & positive & 533 & 534 \\
\hline Malvidin 3-(6-t-caffeoyl-glucoside & 29.30 & positive & 654 & 655 \\
\hline Cyanidin 3-(6-p-coumaroyl)-glucoside & 29.85 & positive & 594 & 595 \\
\hline Petunidin 3-(6-p-coumaroyl)-glucoside & 30.35 & positive & 624 & 625 \\
\hline Malvidin 3-(6-p-coumaroyl)-glucoside & 33.05 & positive & 638 & 639 \\
\hline Vitisin A Malvidin 3-O-glucoside & 18.02 & positive & 560 & 561 \\
\hline Vitisin B Malvidin 3-O-glucoside & 19.53 & positive & 516 & 517 \\
\hline
\end{tabular}

${ }^{\mathrm{a}}$ Compounds coeluted, ${ }^{\mathrm{b}}$ Compounds coeluted. ${ }^{1}$ It could be glucoside or galactoside of laricitrin. 
The studied compounds belong to different phenolic families, such as phenolic acids, stilbenes, flavanols, flavonols and anthocyanins. A multi-objective function had been defined as a criterion for obtaining a satisfactory compromise among number of compounds separated, resolution and analysis time. Only the most important of these families were measured, taking into account different aspects like their abundance in wines, contribution in reactions related with color stabilization and importance in human health. The chromatographic conditions were adapted from the Cozzolino et al. (2004) for red wines, with the addition of a mass spectrometer detector. The samples were filtered through a PVDF Durapore filter of $0.45 \mu \mathrm{m}$ (Millipore, Bedford, MA) and $20 \mu \mathrm{L}$ were injected into an Agilent 1200 high performance liquid chromatograph (HPLC, Palo Alto, CA) equipped with a Diode Array Detector (DAD, Agilent G1315D) and a Mass Spectrometer (6130 Quadrupole LC/MS, G1956B (SL)) multimode electrospray and atmospheric pressure chemical ionization (MM-ESI/APCI-MS) system, coupled to an Agilent Chem Station (version B.03.01) data-processing station. Separation was performed on a reversed-phase Zorbax-Eclipse XDB-C18 $(4.6 \mathrm{~mm}$ x $150 \mathrm{~mm}, 5 \mu \mathrm{m}$ particle sizes) and a precolumn of the same material at $30^{\circ} \mathrm{C}$. The HPLC grade solvents used were water/formic acid/acetonitrile (97.5:1.5:1, v/v/v) as solvent $\mathrm{A}$ and acetonitrile/formic acid/solvent $\mathrm{A}(78.5: 1.5: 20, \mathrm{v} / \mathrm{v} / \mathrm{v})$ as solvent B. The elution gradient for solvent B was as follows: $0 \mathrm{~min}, 5 \% ; 2 \mathrm{~min}, 10 \% ; 7 \mathrm{~min}, 14.5 \% ; 10 \mathrm{~min}$, $18.5 \%$; $12 \mathrm{~min}, 20 \%$; $17 \mathrm{~min}, 20 \%$; $28 \mathrm{~min}, 30 \%$; $30 \mathrm{~min}, 30 \%$; $32 \mathrm{~min}, 50.5 \%$; $38 \mathrm{~min}, 80 \%$; $40 \mathrm{~min}, 100 \%$. The system was equilibrated with the starting conditions during 10 minutes prior to injection of the next sample. The flow rate was $0.5 \mathrm{~mL} \mathrm{~min}^{-1}$.

Phenolic acids, stilbenes and flavanols detection was carried out with the DAD detector by comparison with the corresponding UV-vis spectra and retention time of their pure standards in the chromatogram. Standard of piceid-t-resveratrol were not available, so it was tentatively identified by spectral parameters (Jeandet, 1997). $T$-caftaric acid and $t$-coutaric acid neither were available, so they were identified with the molecular ion and the spectral parameters, which were very close to their analogous caffeic and coumaric acids (Peña-Neira, Hernández, García-Vallejo, Estrella, \& Suarez, 2000). Compounds were quantified and identified at different wavelength: (+) catechin, (-)-epicatechin, gallic acid and syringic acid at $280 \mathrm{~nm}$; vanillic acid at $256 \mathrm{~nm}$; $t$-caffeic acid and caftaric acid at $324 \mathrm{~nm}$, while $t$-resveratrol, piceid-t-resveratrol, $p$-coumaric acid and $t-p$-coutaric acid were quantified at $308 \mathrm{~nm}$.

The flavonols and anthocyanins whose standard were not available were identified on the basis of their molecular ion (showed in Table 1, including also the hydroxycinnamic ester acids, altogether with the ionization mode) by electrospray ionization mass spectrometry (MM-ESI-MS) and the bibliography, according to UV-vis spectra and elution order (Castillo-Muñoz, González, Alonso, Romero, \& Gutiérrez, 2009). The parameters employed for MM-ESI-MS were: dry gas, $\mathrm{N}_{2}, 10 \mathrm{~mL} / \mathrm{min}$; drying temperature, $350{ }^{\circ} \mathrm{C}$; vaporizer temperature, $200{ }^{\circ} \mathrm{C}$; nebulizer, $55 \mathrm{psi}$; capillary, $2000 \mathrm{~V}$ (positive and negative ionization mode); scan range, $100-700 \mathrm{~m} / \mathrm{z}$. Negative mode was used in the identification of hydroxycinnamic ester acids and flavonols, while positive mode was used in anthocyanins. Quantification was done using the spectra obtained by DAD; flavonols at $360 \mathrm{~nm}$ and anthocyanins at $520 \mathrm{~nm}$.

For quantification, calibration curves were obtained with solutions of the available standards in ethanol-water $\left(12 \% \mathrm{v} / \mathrm{v}, \mathrm{pH}=3.6,5 \mathrm{~g} \mathrm{~L}^{-1}\right.$ tartaric acid). T-piceid-resveratrol was expressed as $t$-resveratrol equivalents, $t$-caftaric acid as $t$-caffeic acid, $t$ - $p$-coutaric acid as $p$-coumaric acid, the flavonol glycosides were quantified as Q-3-G equivalents, myricetin as quercetin equivalent and the anthocyanins as Mv-3-G equivalents.

\subsubsection{Total Phenolic Content, Total Anthocyanins and Color Intensity Determination by UV-vis Spectrophotometry}

Parameters such as total phenolic index (TPI), total anthocyanins (TA) and color intensity (CI) were measured with a Lambda 25 UV-vis spectrophotometer (Perkin Elmer, Norwalk, CT). In all cases, samples were first filtered through a PVDF Durapore filter of $0.45 \mu \mathrm{m}$ (Millipore, Bedford, MA). TPI was determined at $280 \mathrm{~nm}$ according to Singleton \& Rossi (1965), TA was measured at $520 \mathrm{~nm}$ according to Puissant-Leon and CI was determined following Glories method measuring absorbance at 420, 520, and $620 \mathrm{~nm}$ (Glories, 1984).

\subsection{Sensorial Analysis}

Three visual phase descriptors and spicy aromatic series were evaluated by a panel of eight expert judges between 30 and 55 years old, after alcoholic, malolactic fermentation and after six months. The panellists rated each attribute on a scale from 1 (absence) to 7 (maximum presence).

\subsection{Statistical Analysis}

The statistical analysis of the data was performed using SPSS Version 19.0 statistical package for Windows (SPSS, Chicago, IL). Phenolic compounds data were processed using variance analysis (ANOVA). Differences 
between means were compared using the least significant difference (LSD) test at a 0.05 probability level. Statgraphics Plus 5.1 (STSC Inc., Rockville, MD, USA) was used to perform the simple regression and principal component analyses.

\section{Results and Discussion}

\subsection{Eugenol and Guaiacol by SBSE-GC-MS}

Concentrations of these volatile compounds in wines from treated grapevines are shown in Table 2. We can observe that the content of both compounds changed depending on the treatment carried out. Regarding to guaiacol, it did not change when $\mathrm{E}$ treatment was carried out, while the concentration increased when $\mathrm{G}$ and $\mathrm{E}+\mathrm{G}$ treatment were applied, regardless of sampling time, being in the last case when the highest change took place ( $1150 \%$ respect to control, while it was $210 \%$ when only $\mathrm{G}$ was applied). On the other hand, the eugenol content also varied depending on the treatment. In $G$ wines, eugenol concentration was higher than in control. Although in both cases ( $\mathrm{G}$ and control) concentrations were much lower comparing with $\mathrm{E}$ and $\mathrm{E}+\mathrm{G}$ wines, the increase in $\mathrm{G}$ wines was about $250 \%$ respect to control), the increase in percentage was high, although in absolute value the differences ranged between $4-5 \mu \mathrm{g} / \mathrm{L}$, while greater increase of that compound were produced by the effect of $E$ treatment $(20000 \%)$. Eugenol also increased in a higher degree when the $E+G$ treatment were carried out, as happened with guaiacol. In the three treatments $(\mathrm{E}, \mathrm{G}, \mathrm{E}+\mathrm{G})$, the same quantity of eugenol and guaiacol was applied $(0.6 \%(\mathrm{v} / \mathrm{v}))$, but the increase of both volatiles in wines was different, depending on the compound and treatment carried out. Maybe the variations could be due to the fact that the assimilation of these exogenous compounds by the plant was different, as well the translocation step or the way in which the volatiles were stored in the plant. Some studies suggest that glycosylation is one of storage medium of volatile compounds, which limits the toxicity of some of them, as the glycosides are much more water soluble than aglycons, so they are considered to be vectors for the transport and accumulation of such compounds in plants (Winterhalter \& Skouroumounis, 1997). The aroma glycosidic precursors are a diverse group of odorless compounds which can suffer hydrolysis by acids or enzymes, giving the odour-active aglycones (Gunata, Bayonove, Baumes, \& Cordonnier, 1985). An increase of glycosylated forms of guaiacol and 4-methylguaiacol were observed when grapevines were exposed to smoke from the fire forests (Singh et al., 2011). On the other hand, when both volatiles were applied together, higher volatile concentration of each compound was produced in wines than when they were applied independently. Moreover, similar concentrations of each compound were observed at different sampling times. This synergic effect could be due to the fact that plants were stimulated to produce more of these compounds and the absorption was higher or maybe there was a different degree in the hydrolysis of their precursors, giving their aglycones, so higher proportion of volatile compounds was generated. Anyway, these results suggest that the application of exogenous eugenol and guaiacol compounds modified the composition of grapes in a similar way that was observed with Verdejo and Petit Verdot wines after oak extract application (Martínez-Gil et al., 2012). Eugenol and guaiacol concentrations in wines overcame their respectively odor threshold, which provides to wines nice aromatic spicy notes. Eugenol is a component of clove (85-95\%) and other spices such as basil and cinnamon, which are used as food flavouring; it is also used as food additives, as well in dental material. On the other hand, guaiacol is a component of the smoke employed to conserve food (smoke food). Although eugenol and guaiacol concentrations in wines were elevated, they are much lower than their toxicity level (DL $\mathrm{D}_{50}$ orally in rats: 2680 and $725 \mathrm{mg} \mathrm{kg}^{-1}$ respectively (The Merck Index)), which means a person $(65 \mathrm{~kg})$ should drink $3 \cdot 10^{5} \mathrm{~L}$ and $4 \cdot 10^{4} \mathrm{~L}$ of wine to reach those concentration of eugenol and guaiacol, respectively.

Table 2. Volatil content of guaiacol and eugenol in the wines produced from the treated grapevines at the end of the alcoholic fermentation (AF), malolactic fermentation (MLF) and after 6 months of MLF

\begin{tabular}{llllllll}
\hline \multirow{2}{*}{ Treatment } & \multicolumn{3}{c}{ Guaiacol content $(\boldsymbol{\mu g} / \mathbf{L})$} & & \multicolumn{3}{c}{ Eugenol content $(\boldsymbol{\mu g} / \mathbf{L})$} \\
\cline { 2 - 5 } \cline { 7 - 8 } \cline { 7 - 8 } & AF & MLF & $\mathbf{6 ~ m o n t h s}$ & & AF & MLF & 6 months \\
\hline control & $48 \pm 12^{\alpha, \mathrm{a}}$ & $55 \pm 10^{\alpha, \mathrm{a}}$ & $59 \pm 3^{\alpha, \mathrm{a}}$ & & $1.49 \pm 0.14^{\alpha, \mathrm{a}}$ & $1.87 \pm 0.21^{\beta, \mathrm{a}}$ & $1.72 \pm 0.13^{\alpha \beta, \mathrm{a}}$ \\
$\mathbf{E}$ & $46 \pm 11^{\alpha, \mathrm{a}}$ & $51 \pm 6^{\alpha, \mathrm{a}}$ & $43 \pm 6^{\alpha, \mathrm{a}}$ & & $250 \pm 40^{\alpha, \mathrm{c}}$ & $310 \pm 20^{\alpha, \mathrm{c}}$ & $280 \pm 30^{\alpha, \mathrm{c}}$ \\
$\mathbf{G}$ & $150 \pm 10^{\alpha, \mathrm{b}}$ & $180 \pm 20^{\alpha, \mathrm{b}}$ & $150 \pm 14^{\alpha, \mathrm{b}}$ & & $5.4 \pm 0.7^{\alpha, \mathrm{b}}$ & $7.0 \pm 0.6^{\beta, \mathrm{b}}$ & $6.6 \pm 0.9^{\alpha \beta, \mathrm{b}}$ \\
$\mathbf{E}+\mathbf{G}$ & $600 \pm 40^{\alpha, \mathrm{c}}$ & $560 \pm 50^{\alpha, \mathrm{c}}$ & $550 \pm 30^{\alpha, \mathrm{c}}$ & & $530 \pm 44^{\alpha, \mathrm{d}}$ & $530 \pm 43^{\alpha, \mathrm{d}}$ & $570 \pm 40^{\alpha, \mathrm{d}}$ \\
\hline
\end{tabular}


All parameters are given with their standard deviation $(n=4)$. E: wine from grapevines eugenol treatment; $G$ : wine from grapevines guaiacol treatment; $\mathrm{E}+\mathrm{G}$ : wine from grapevines eugenol and guaiacol treatment. Different Greek letters in the same row indicate differences among the sampling times, while different Latin letters in the same column indicate differences in the concentration among the wines (level of significance: $p<0.05$ ).

\subsection{Oenological Parameters}

Oenological parameters were measured in the different sampling times to check the evolution of the wines (Table 3). pH, total acidity and volatile acidity values of all samples were common for red wines (Ribéreau-Gayon, P. (2000)) . However, it can be observed that wines from treatments had lower pH values than control wine, meaning that treatments improved the microbiological stability of wines. On the other hand, wines from $\mathrm{G}$ treatment had the lowest alcoholic degree, which could be related with the negative effect in the sugar accumulation of grapes observed by Kennison, Wilkinson, Pollnitz, Williams, and Gibberd (2009) which studied grapevine exposure, being the guaiacol a component of the smoke and present at elevated concentration in wines from smoke-affected grapes (Singh et al., 2011). Anyway, G treatment seems to affect the primary metabolism of the plant because the wines obtained had also less acidity than wines from the other treatments. The same behavior was observed at 3 sampling times.

Table 3. Oenological parameters in wines at the end of the alcoholic fermentation (AF), after malolactic fermentation (MLF) and after six months

\begin{tabular}{|c|c|c|c|c|}
\hline \multicolumn{5}{|c|}{$\mathrm{AF}$} \\
\hline Treatment & $\mathrm{pH}$ & titratable ac. & volatile ac. & ${ }^{\circ} \mathrm{A}(\% \mathrm{v} / \mathrm{v})$ \\
\hline Control & $3.80 \pm 0.03^{\mathrm{c}}$ & $5.60 \pm 0.11^{b}$ & $0.46 \pm 0.05^{\mathrm{b}}$ & $13.32 \pm 0.48^{\mathrm{b}}$ \\
\hline $\mathrm{E}$ & $3.69 \pm 0.01^{\mathrm{b}}$ & $5.19 \pm 0.41^{\mathrm{a}}$ & $0.22 \pm 0.01^{\mathrm{a}}$ & $13.25 \pm 0.34^{\mathrm{b}}$ \\
\hline G & $3.65 \pm 0.01^{\mathrm{a}}$ & $5.04 \pm 0.01^{\mathrm{a}}$ & $0.22 \pm 0.01^{\mathrm{a}}$ & $12.08 \pm 0.05^{\mathrm{a}}$ \\
\hline $\mathrm{E}+\mathrm{G}$ & $3.68 \pm 0.01^{\mathrm{a}, \mathrm{b}}$ & $5.68 \pm 0.04^{b}$ & $0.26 \pm 0.00^{\mathrm{a}}$ & $13.65 \pm 0.08^{b}$ \\
\hline \multicolumn{5}{|c|}{ MLF } \\
\hline Treatment & $\mathrm{pH}$ & titratable ac. & volatile ac. & ${ }^{\circ} \mathrm{A}(\% \mathrm{v} / \mathrm{v})$ \\
\hline Control & $3.96 \pm 0.01^{\mathrm{c}}$ & $4.81 \pm 0.06^{\mathrm{a}}$ & $0.56 \pm 0.15^{\mathrm{a}}$ & $13.21 \pm 0.25^{\mathrm{b}}$ \\
\hline $\mathrm{E}$ & $3.86 \pm 0.01^{\mathrm{b}}$ & $5.11 \pm 0.08^{b}$ & $0.42 \pm 0.06^{\mathrm{a}}$ & $13.29 \pm 0.13^{b, c}$ \\
\hline G & $3.82 \pm 0.01^{\mathrm{a}}$ & $4.82 \pm 0.04^{\mathrm{a}}$ & $0.54 \pm 0.08^{\mathrm{a}}$ & $11.93 \pm 0.11^{\mathrm{a}}$ \\
\hline $\mathrm{E}+\mathrm{G}$ & $3.86 \pm 0.01^{\mathrm{b}}$ & $5.20 \pm 0.05^{\mathrm{b}}$ & $0.46 \pm 0.00^{\mathrm{a}}$ & $13.62 \pm 0.19^{\mathrm{c}}$ \\
\hline \multicolumn{5}{|c|}{6 MONTHS } \\
\hline Treatment & $\mathrm{pH}$ & titratable ac. & volatile ac. & ${ }^{\circ} \mathrm{A}(\% \mathrm{v} / \mathrm{v})$ \\
\hline Control & $3.96 \pm 0.02^{\mathrm{c}}$ & $4.66 \pm 0.08^{\mathrm{a}, \mathrm{b}}$ & $0.61 \pm 0.01^{\mathrm{b}}$ & $13.02 \pm 0.15^{b}$ \\
\hline $\mathrm{E}$ & $3.81 \pm 0.01^{\mathrm{a}, \mathrm{b}}$ & $5.82 \pm 0.15^{\mathrm{c}}$ & $0.59 \pm 0.06^{\mathrm{b}}$ & $13.18 \pm 0.18^{\mathrm{c}}$ \\
\hline G & $3.80 \pm 0.02^{\mathrm{a}}$ & $4.53 \pm 0.08^{\mathrm{a}}$ & $0.51 \pm 0.01^{\mathrm{a}}$ & $11.80 \pm 0.14^{\mathrm{a}}$ \\
\hline $\mathrm{E}+\mathrm{G}$ & $3.84 \pm 0.02^{\mathrm{b}}$ & $4.81 \pm 0.08^{\mathrm{b}}$ & $0.57 \pm 0.03^{\mathrm{a}, \mathrm{b}}$ & $13.44 \pm 0.08^{\mathrm{b}}$ \\
\hline
\end{tabular}

All parameters are given with their standard deviation $(n=4)$. E: wine from grapevines eugenol treatment; G: wine from grapevines guaiacol treatment; $\mathrm{E}+\mathrm{G}$ : wine from grapevines eugenol and guaiacol treatment. Titratable acidity is expressed in $\mathrm{g} / \mathrm{L}$ of tartaric acid, while volatile acidity is expressed as $\mathrm{g} / \mathrm{L}$ of acetic acid and alcoholic degree. Different letters in the same column indicate significant differences among the wines (level of significance: $\mathrm{p}<0.05$ ).

\subsection{Phenolic Compounds Determination by HPLC-DAD-MS}

The total content of the phenolic acids, as well as the content of the hydroxybenzoic acids (gallic, vanillic and syringic acids), hydroxycinnamic acids (caffeic and coumaric acids) and the hydroxycinnamic acid esters (caftaric and t-coutaric acids) are presented in Figure 1A (a-d). In general, the total phenolic acids content was 
higher in wines from treatments than in control and at the end of the malolactic fermentation, especially after six months of this (Figure 1A (a)).

The concentration of hydroxybenzoic acids (Figure 1A(b)) also was different among the studied wines. Their content was higher in $\mathrm{E}$ and $\mathrm{E}+\mathrm{G}$ wines than in control and $\mathrm{G}$ wines. Except vanillic acid, no other hydroxybenzoic acid concentrations were modified by the effect of the $G$ treatment (data not shown), while $E$ and $\mathrm{E}+\mathrm{G}$ ones produced an increase in the content of all of them. They also increased after malolactic fermentation, which was due to the contribution of gallic acid, since vanillic and syringic acids remained constant through the samplings (data not shown). Similar values and behaviour of hydroxybenzoic acids in Monastrelll wines was reported by Lorenzo, Pardo, Zalacain, Alonso, and Salinas (2005).

The content of hydroxycinammic acids (Figure $1 \mathrm{~A}(\mathrm{c})$ ) after alcoholic fermentation was slightly higher in $\mathrm{E}$ and $\mathrm{E}+\mathrm{G}$ wines than in control and $\mathrm{G}$ wines, as happened with the hydroxybenzoic acids. However, at the end of the malolactic fermentation and after six month of this, they were considerably more abundant in $\mathrm{E}$ wine. Hydroxycinnamic acids are copigments, involved in covalent reactions with anthocyanins to give more stable compounds. Darías-Martín et al. (2002) showed the strong copigmentation effect when additions of $t$-caffeic acid in pre-fermentation step of Listan Negro and Negramoll wines were made. On the other hand, prefermentation addition of $t$ - $p$-coumaric acid increased the absorbance at $520 \mathrm{~nm}$ in Cabernet Sauvignon wines, while caffeic acid addition had the opposite effect, which showed that their effect depends on the grape variety (Schwarz et al., 2005). T-caffeic and $t$ - $p$-coumaric acids are present in wine as a consequence of the hydrolysis of their derivatives, as can be their respective hydroxycinnamoyltartaric acids present in grapes and from the hydrolysis of acylated anthocyanins (Monagas, Bartolomé, \& Gómez-Cordovés, 2005). Lorenzo et al. (2005) reported the content of hydroxycinnamic acids in Monastrell wines, which increased from the alcoholic fermentation to after 9 months. After alcoholic fermentation the content of hydroxycinnamic ester acids (Figure 1A(d)) was higher in the wines from treatments than in control. After malolactic fermentation there was a slight decrease of their concentration in all wines, except for $\mathrm{E}$ wines, which had a great loss of $t$-caftaric and $t$-coutaric acids, which means that a large hydrolysis of these compounds took place during malolactic fermentation. The marked changes of both compounds could explain the above increase of $t$-caffeic and $t$ - $p$-coumaric acids. On the other hand, hydroxycinnamic esters did not present changes after six months respect to malolactic fermentation. Zafrilla et al. (2003) showed a slight decrease of these esters in Monastrell wines, but after 7 month storage period.

The studied stilbenes were $t$-resveratrol and its glucoside piceid-t-resveratrol or $t$-resveratrol 3-O- $\beta$-D-glucopyranoside. T-resveratrol has antioxidant properties and beneficial effects for human health, with hepatic and cardio protective properties, among others (Rotches-Ribalta, Andres-Lacueva, Estruch, Escribano, \& Urpi-Sarda, 2012). In our study the standard of $t$-resveratrol aglycone allows us to confirm its identity in the samples, but the piceid compound is tentatively identified according to the bibliography and the spectra obtained at $308 \mathrm{~nm}$ (Jeandet, 1997). After the alcoholic fermentation, total content of stilbenes (Figure 1B(a)) was higher in wines from treatments than in control, suggesting that the compounds applied by foliar treatments stimulate the stilbenes synthesis, as well their presence in wines. The same behaviour was observed at the end of the malolactic fermentation and 6 month after, especially in wines from eugenol treatments, being an increase of $t$-resveratrol as well of its piceid glucoside. (Figures 1B (b,c)). Other preharvest chemical treatments such as benzothiadiazole and chitosan (Iriti, Rossoni, Borgo, \& Faoro, 2004) increased the content of $t$-resveratrol in grapes. Although the increase of stilbenes in the grapes could be due to a stress produced to the plants (Roldán, Palacios, Caro, \& Pérez, 2003), it also depended on the chemical nature of the compounds applied, such as eugenol which produced the highest increase of stilbenes. The synthesis of the piceid depends on $t$-resveratrol because it is the initial compound in the stilbene pathway, which can be glycosilated into a non-toxic compound such as piceid-t-resveratrol (Pezet, Gindro, Viret, \& Spring, 2004). So, the results suggest that eugenol and guaiacol can act as stimulating agents to enhance the content of $t$-resveratrol and their derivatives in wines.

The flavanols studied were the monomers (+)-catechin and (-)-epicatechin (Figure 1C (a,b,c)). The total concentrations of these compounds were higher in wines from treatments than in control wine for all sampling times. The highest content of them was always in $\mathrm{E}$ wine. In control wine, the total flavanols content remained without significant changes through the time, but in wines from treatments, a decrease was observed with time. Similar decreased was observed by other authors (Lorenzo et al., 2005). Comparing the individual profile of $(+)$-catechin and (-)-epicatechin, it was observed that $(+)$-catechin content was always the lowest in control wine, while it was the highest in $\mathrm{E}$ wine. $\mathrm{G}$ and $\mathrm{E}+\mathrm{G}$ wines had similar concentration in the three samplings carried out. After 6 months, there was a slight decrease of (+)-catechin in all wines. The content of (-)-epicatechin at the end of the alcoholic fermentation was also the highest in $\mathrm{E}$ wine, but in this case its concentration decreased further 
than in the others wines, especially during malolactic fermentation. These compounds form complex polymers and can combine with some anthocyanins to give more stable pigments and as consequence more stable color in wines (González-Manzano et al., 2009). Maybe the decreased of free (+)-catechin and (-)-epicatechin in wine is due to a loss by solid precipitation, oxidation or polimerization reactions. On the other hand, flavanols concentration can increase in wines due to the fact that they can be liberated from galloylated precursors (effect which could be related with the increase of gallic acid along the different samplings commented above). So, it is possible that a combination of degradation and liberation of these compounds took place in wines from treated vineyards.

Flavonols are yellow pigments, which are also involved in the phenomenon of copigmentation (Boulton, 2001), contributing to color stabilization in red wines. The flavonols profiles of the studied wines are showed in Figure 1D (a-f). Among the 12 flavonols studied there are aglycones, glucosides, glucuronides and galactosides of myricetin, quercetin, laricitrin and syringetin (Table 1). The flavonols 3-O-glycosides suffer diverse degree of hydrolysis depending on the different compounds, so they are classified according to the type of aglycone (myricetin, quercetin, laricitrin, syringetin and kaempferol) and the glycosylation (glycosilated and aglycone) to discussion. The total content of the different flavonols (aglycone + glycosilated) (Figure 1D(a)) changed depending on the studied samples, but the proportion of the diverse types was similar. It can be observed that Monastrell wines had high proportion of quercetin-type flavonols, quercetin-glucuronide being the most abundant (data not shown), while quercetin-glucoside was in very low concentration, as it has been reported in previous work (Hermosín-Gutiérrez, Castillo-Muñoz, Gomez-Alonso, \& García-Romero, 2011). This fact could be due because quercetin 3-O-glucoside is very labile and it is hydrolyzed to a large extent (Castillo-Muñoz, Gómez-Alonso, García-Romero, \& Hermosín-Gutiérrez, 2007). There was also high proportion of myricetin 3-O-glycosides, having similar profile to quercetin type (high proportion of myricetin 3-O-glucuronide). On the other hand, although kaempferol 3-glucoside could be guaranteed by comparison with authentic standard, peak was not found in the samples and no other flavonol 3-O-glycoside of kaempferol was identified in the studied wines. Moreover, kaempferol aglycone was in very low proportion in comparison with the other flavonols $(0.4$ $1.6 \%$ of the total flavonols). At the end of the alcoholic fermentation, the total flavonols content in $\mathrm{E}$ and $\mathrm{E}+\mathrm{G}$ wines was slightly higher than in control and $\mathrm{G}$ wines. There was a little decreased of them through the sampling times, except to $\mathrm{E}+\mathrm{G}$ wine, which remained constant after malolactic fermentation. On the other hand, flavonols 3-O glycosides decreased with the time in the samples, while the quantity of aglycones increased, as it was expected due to hydrolysis phenomenon. Laricitrin and syringetin flavonols were in low quantity and their behaviour in wines was similar. After 6 months of the alcoholic fermentation, it was a high increase of aglycones in $\mathrm{E}$ wines (Figure1D(f)), influencing in the total content of flavonols. It was also observed an increase in control and $\mathrm{G}$ wines after six months, although their total flavonols content decreased at this sampling time.

The individual profile of 11 monomeric anthocyanins was studied (Table 1), which were grouped in non-acylated (glucoside anthocyanins: delphinidin, cyanidin, petunidin, peonidin and malvidin 3-O-glucoside), acetyl (peonidin and malvidin 3-O-(6-acetyl)-glucosides) caffeoyl (malvidin 3-O-(6-t-caffeoyl)-glucoside) and coumaril-derivatives (cyanidin, petunidin and malvidin 3-O-(6-p-coumaroyl)-glucosides). Figure 1E(a-e) shows their content in the wines. After alcoholic fermentation, the total anthocyanins content was higher in wines from treated grapevines than in control one, being more abundant in $\mathrm{E}$ and $\mathrm{E}+\mathrm{G}$ wines, meaning that treatments could favour their synthesis or extraction into the wines. After malolactic fermentation the total content of these pigments decreased in all wines, although the highest reduction took place in E wines. However, control and G wines had still the lowest values of anthocyanins. After 6 months all wines had the lowest quantities of total anthocyanins and decreased the differences in their content among the wines; the total anthocyanins content of $\mathrm{E}$ and $\mathrm{E}+\mathrm{G}$ wines was similar to control, while in $\mathrm{G}$ wines it was the lowest content. Glucoside anthocyanins were the most abundant in wines (Figure 1E(b)), so the wine profile of them was similar to that of total anthocyanins. Acetyl anthocyanins are pigments derived from the glucoside anthocyanins, whose content is showed in Figure $1 \mathrm{E}(\mathrm{c})$. The lowest content was also found in control wines. At the end of the malolactic fermentation the levels of acetyl anthocyanins decreased in wines, except to control, which remained constant, but after 6 months, they decreased in all the wines, being $\mathrm{G}$ wines those with the lowest content of acetyl anthocyanins. Regarding to coumaroyl anthocyanins (Figure 1E(d)), as happened in the above cases, after alcoholic fermentation the highest content was in $\mathrm{E}$ wine, but the highest decreased produced after malolactic fermentation was also for this wine. It seems feasible to think that the strongly increased of the $p$-coumaric acid (commented above) in E wine after malolactic fermentation was also due to the degradation of the coumaroyl pigments, besides the hydrolysis of $t$ - $p$-coutaric acid. 
Caffeoyl anthocyanins, derived pigments from glucoside anthocyanins, were found in low quantity in wines, being between the $0.4-7 \%$ of the total anthocyanins content (Figure 1E(e)). The behavior of this pigment was similar than that showed to glucoside anthocyanins, except in control, which had the highest content of malvidin 3-O-(6-t-caffeoyl)-glucoside. The contents of t-caffeic acid and Mv-3-G (precursors of this pigment) were higher in $\mathrm{E}$ and $\mathrm{E}+\mathrm{G}$ wines than in control, while the caffeoyl derived pigment content was lower in those wines than in control. This fact could be due to different factors such as its formation was not favored by any reason, the degradation degree in these wines was higher than in control or due to copigmentation process.

Figure $1 \mathrm{~F}(\mathrm{a}-\mathrm{c})$ shows the content of vitisines $\mathrm{A}$ and $\mathrm{B}$ of $\mathrm{Mv}-3-\mathrm{G}$ in the wines. Vitisines are no present in fresh grapes, so their formation and existence in wines depend on the conditions of wines and the presence of the secondary metabolic products, such as pyruvate and acetaldehyde (Morata, Calderón, González, Gómez-Cordovés, \& Suárez, 2007). At the end of the alcoholic fermentation the total vitisins concentration was different depending on the treatment carried out. In this case, wine from guaiacol grapevines treatment and control wine had the highest content. However, during malolactic fermentation there was a degradation of them in all wines and after 6 months, control was the wine with higher content of them. Vitisin A and vitisin B were with similar levels after alcoholic fermentation, although the differences appreciated in the total content between wines in the first sampling time were due to vitisin B in a large extent, whose concentration were much higher in $\mathrm{G}$ and control wines than in the others. On the other hand, after malolactic fermentation these differences were due to vitisin A content, which decreased, although in a lesser degree than vitisin B. During malolactic fermentation there was degradation of both pigments, but vitisin A seemed to be more stable than the other. Morata, Gómez-Cordovés, Calderón, \& Suárez (2006) reported that the presence of vitisins is important in color stability of red wines by the effect of their improved resistance to bleaching by sulfur dioxide.

\subsection{Total Phenolic index, total anthocyanins and color intensity by UV-vis spectrophotometry}

Figure 2 shows the values of total phenolic index (TPI), total anthocyanins and color intensity. These parameters have great interest for wineries, because they are used by oenologists for the regular wine control and to take decisions about the winemaking to be employed.

Although the differences of TPI were not very big among the studied wines after the alcoholic fermentation, E and $\mathrm{E}+\mathrm{G}$ wines had higher values, with significant differences respect to control and $\mathrm{G}$ wines. After malolactic fermentation TPI values remained constant or decreased slightly, as occurred with $G$ wines. After 6 months decreased in all wines, being $\mathrm{E}$ and $\mathrm{E}+\mathrm{G}$ those with higher TPI values than control and $\mathrm{G}$ wines. Total anthocyanins content had similar behaviour than TPI, because in all samplings, $\mathrm{E}$ and $\mathrm{E}+\mathrm{G}$ wines had the biggest values. The total anthocyanins content was also bigger in $\mathrm{E}$ and $\mathrm{E}+\mathrm{G}$ wines than in the other ones, being in accordance to the individual anthocyanin results studied above. Moreover, in both cases the highest content was for the wine from grapevines treated with eugenol solution. After malolactic fermentation the level of total anthocyanins decreased in all the wines, as was expected, being $\mathrm{E}$ and $\mathrm{E}+\mathrm{G}$ wines the samples with the highest content of them, while its value was significantly lower in $G$ wine than control one. After 6 months total anthocyanins also decreased in all wines. $\mathrm{E}$ and $\mathrm{E}+\mathrm{G}$ wines remained with bigger values of anthocyanins, but differences among them and control wine decreased at this sampling time.

Color intensity is related to the content of TPI and anthocyanins. Although $\mathrm{E}$ and $\mathrm{E}+\mathrm{G}$ wines had slightly higher color intensity values than control and $\mathrm{G}$ wines, there were significant differences between them. At the end of the malolactic fermentation and after 6 months of this, the color intensity decreased in all samples, being the highest value for $\mathrm{E}$ wines.

In any case, the treatments carried out modified the parameters measured by UV-vis; so, while eugenol produced an increase in the content of TPI, total anthocyanins and the color intensity in wines, the application of guaiacol did not modified these parameters or decreased in their values. 
A

(a) phenolic acids

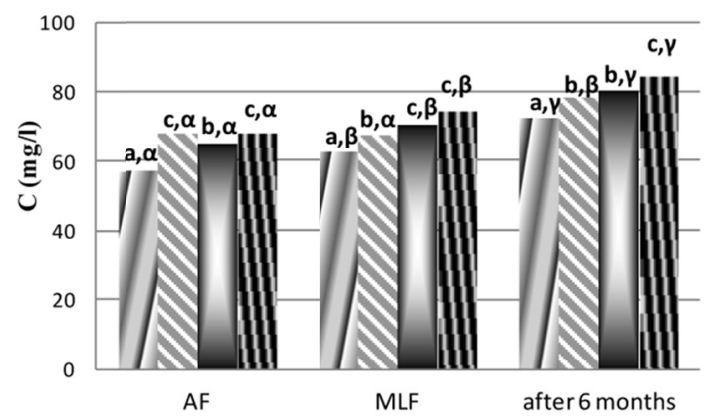

(c) hydroxycinnamic acids

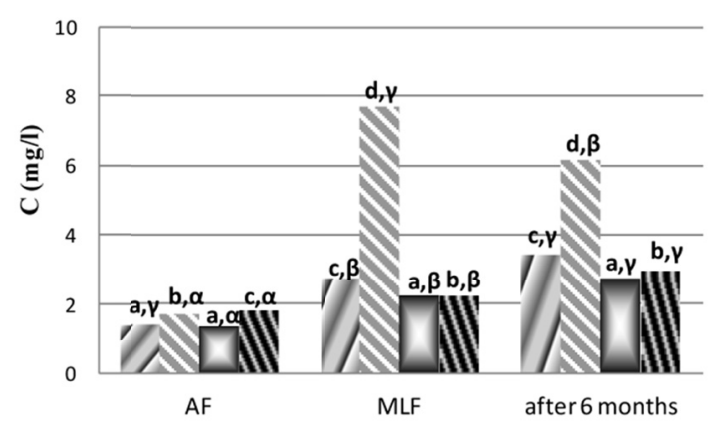

(b) hydroxybenzoic acids

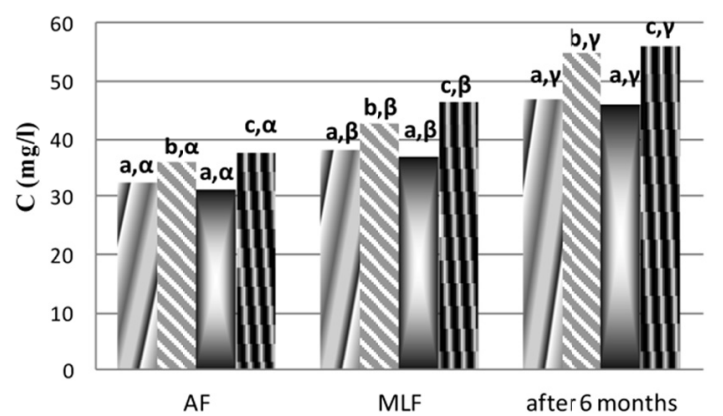

(d) hydroxycinnamic ester acids

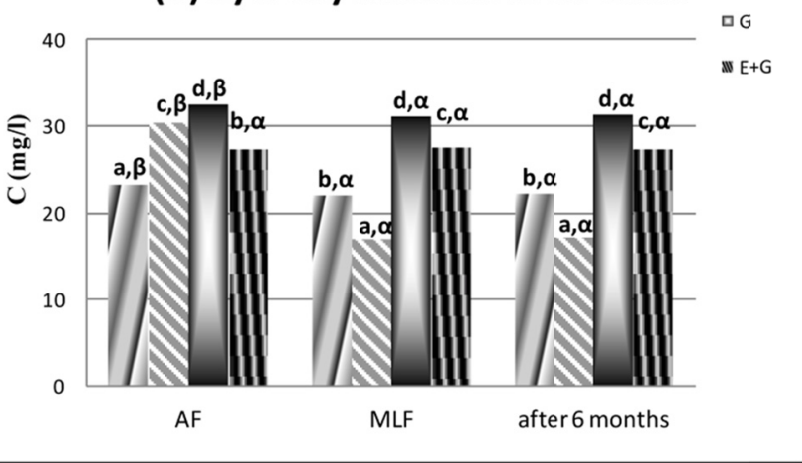

B

(a) stilbenes

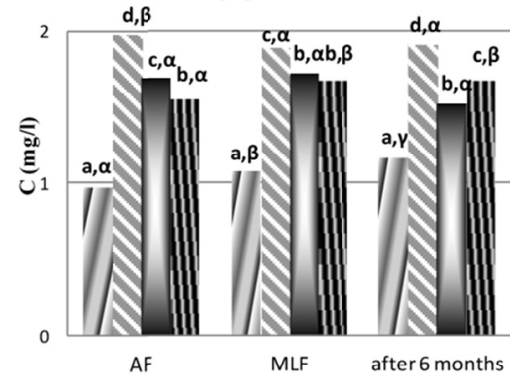

(b) $t$-resveratrol

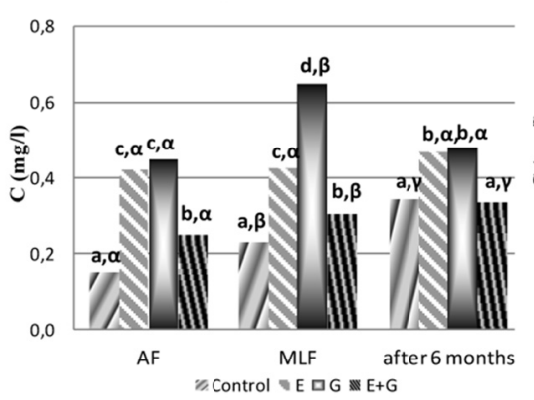

(c) piceid-t-resveratrol

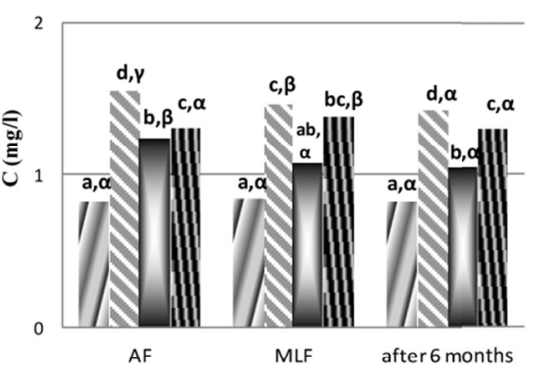

C

(a) total flavanols

(b) (+)-catechin
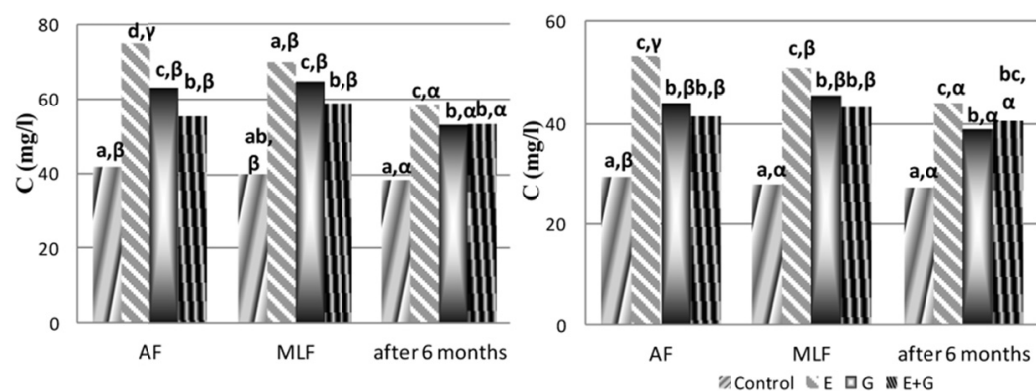

(c) (-)-epicatechin

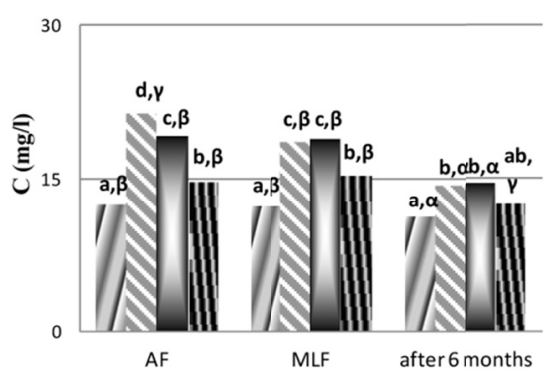




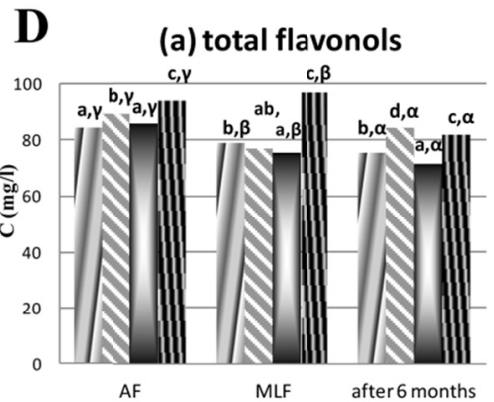

(d) laricitrin 3-O-g type

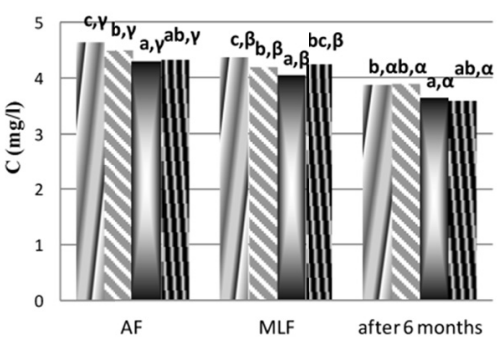

(b) myricetin 3-0-g type

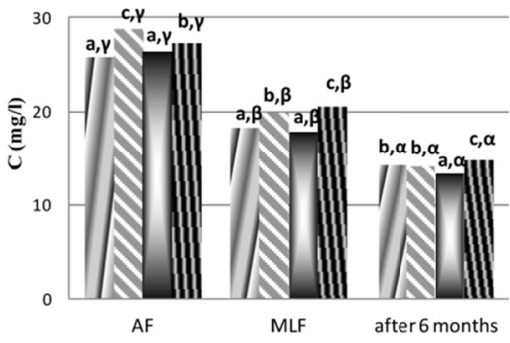

(e) syringetin 3-0-g type



m Control $-E$ a $\quad \mathrm{E}=\mathrm{E}+\mathrm{G}$ (c) quercetin 3-0-g type

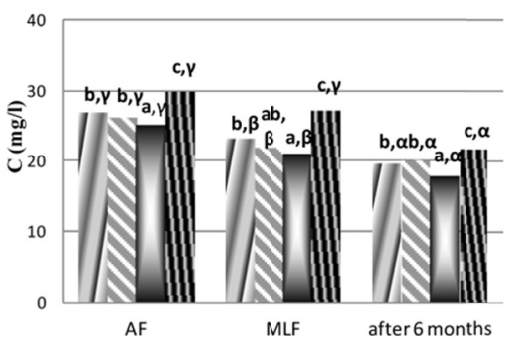

(f) aglycone

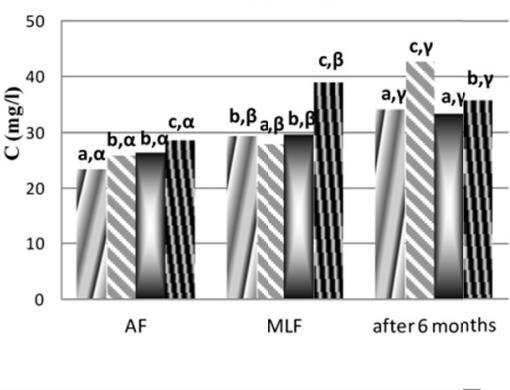

(c) acetyl anthocyanins

\section{E (a) total anthocyanins}

(b) glucoside anthocyanins


(d) coumaroyl anthocyanins

(e) caffeoyl anthocyanins
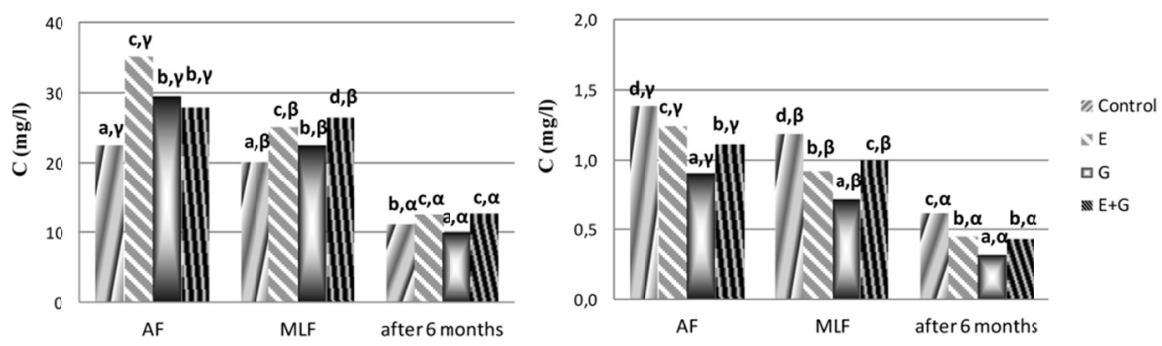

F

(a) total vitisins

(b) vitisin A

(c) vitisin B
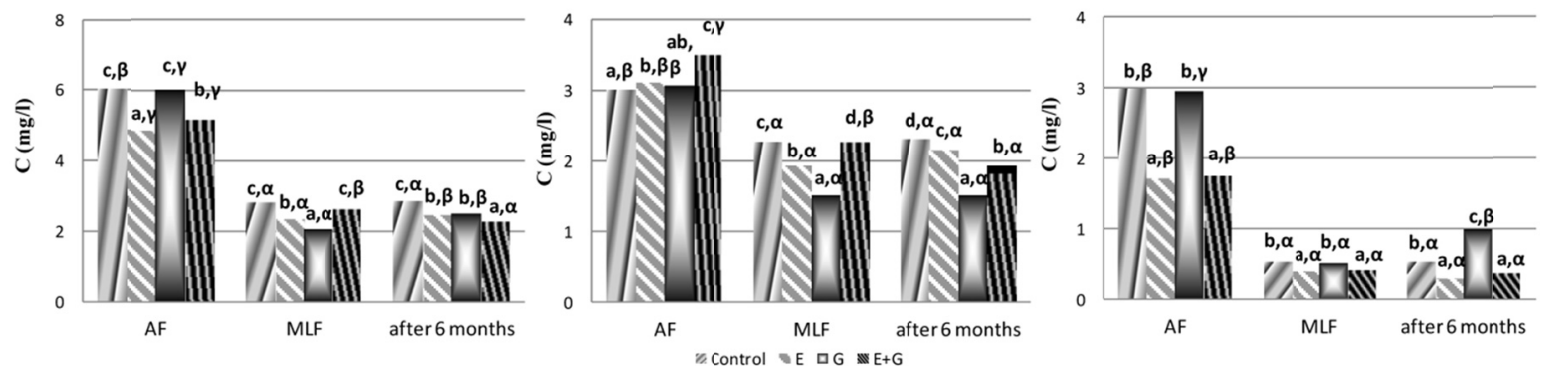

Figure 1. Content of phenolic compounds in wines 
All parameters are given with their standard deviation $(n=4)$. E: wine from grapevine eugenol treatment; G: wine from grapevine guaiacol treatment; $\mathrm{E}+\mathrm{G}$ : wine from grapevine eugenol and guaiacol treatment. A: (a) total phenolic acids, (b) hydroxybenzoic acids, (c) hidroxycinammic acids and (d) hydroxycinnamic ester acids concentration); B: (a) total stilbenes, (b) $t$-resveratrol and (c) piceid- $t$-resveratrol concentration; C: (a) total flavanols, (b) (+)-catechin and (c) (-)-epicatechin concentration; D: (a) total flavonols, (b) myricetin 3-O-g type, (c) quercetin 3-O-g type, (d) laricitrin 3-O-g type (laricitin 3-O-glucoside/galactoside), (e) syringetin 3-O-g type) and (f) aglycone concentration; E: (a) total anthocyanins, (b) glucoside anthocyanins, (c) acetyl anthocyanins, (d) coumaroyl anthocyanins and (e) caffeoyl anthocyanins concentration; F: (a) total vitisins, (b) vitisin A and (c) vitisin B concentration of the studied wines in the different samplings. For each sample, different Latin letter indicate significant differences among the samples, while different Greek letters indicate differences among the sampling time (level of significance: $\mathrm{p}<0.05)$. All parameters are given with their standard deviation $(n=4)$.

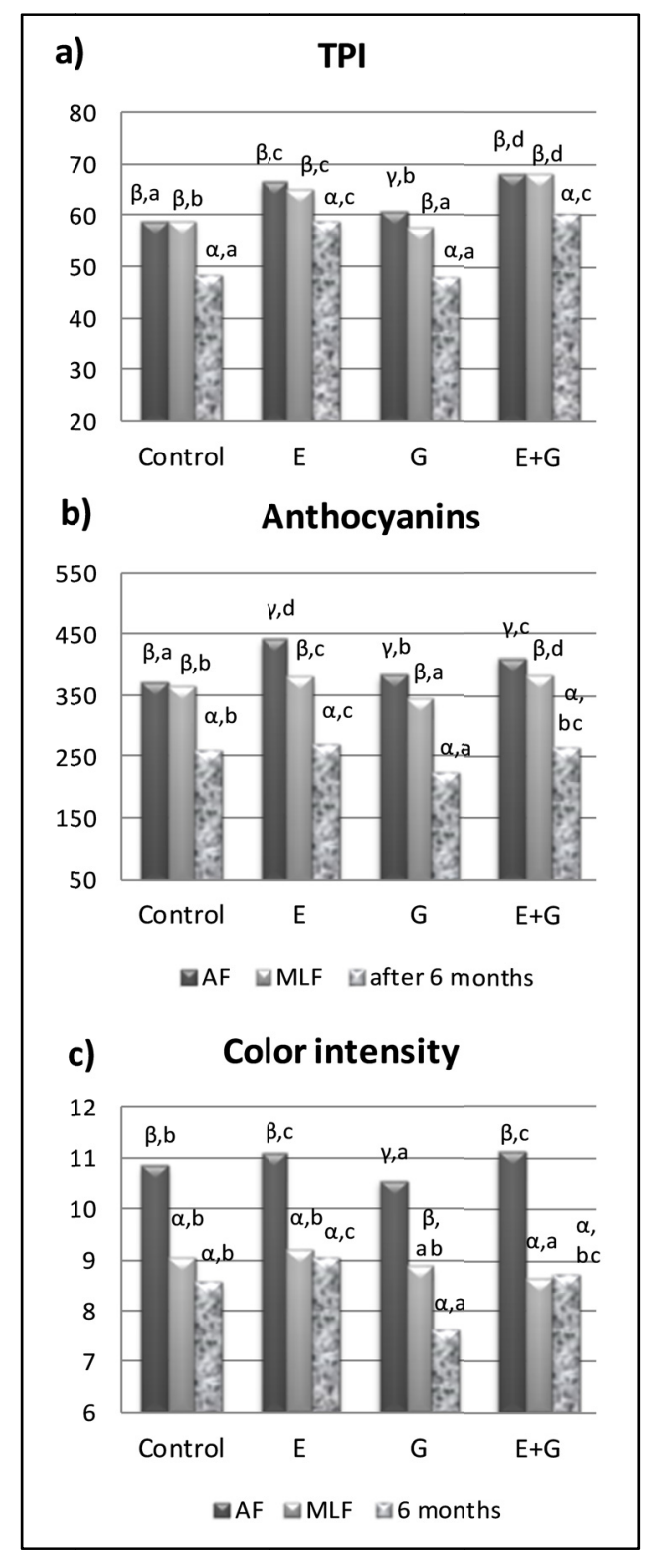

Figure 2. Values of spectrophotometrically measures of, polyphenol total index (TPI), total anthocyanins content and color intensity. E: wine from grapevines eugenol treatment; $\mathrm{G}$ : wine from grapevines guaiacol treatment; $\mathrm{E}+\mathrm{G}$ :

wine from grapevines eugenol and guaiacol treatment. Different Greek letters indicate differences among the sampling times, while different Latin letters indicate differences among the wines (level of significance of $p<0.05$ ) 


\subsection{Sensorial Analysis}

Visual and olfactory profile was done because they are the most linked with the studied parameters. Mean values of the evaluated descriptors are presented in Figure 3 (a-c), showing the blue, red and yellow descriptors (visual phase), which are related to wine quality and can give information about the age of wines. So, a young wine is characterized by having red and blue tones, while with ageing there is a loss of them and higher yellow tones appears (Monagas, Martín-Álvarez, Gómez-Cordovés \& Bartolomé). Judges found color differences among the wines, being red and blue tones higher for $\mathrm{E}$ and $\mathrm{E}+\mathrm{G}$ wines than the other ones, while the highest yellow hue was in control wine. It is important to note that although after six month, judges did not found big differences of red hue among the samples, variations were observed regarding to yellow one. Regards to olfactory score, values of spicy aromatic series are showed in Figure 3d, they are the mean of the total of spicy and clove attributes, because they are linked with eugenol and guaiacol. Differences among wines were appreciated by judges, who found wines from treatments with more spicy notes than control in the three sampling time. Consequently, results showed that foliar treatments over grapevines, especially $\mathrm{E}$ and $\mathrm{E}+\mathrm{G}$, improved the color stability of wines through the time and gave spicy characters to wine.



Figure 3. Visual and olfactory scores of the blue, red, yellow hue and spicy series descriptors of sensorial analysis of wines. E: wine from grapevines eugenol treatment; G: wine from grapevines guaiacol treatment; $\mathrm{E}+\mathrm{G}$ : wine from grapevines eugenol and guaiacol treatment. Different Greek letters indicate differences among the sampling times, while different Latin letters indicate differences among the wines (level of significance: $\mathrm{p}<0.05$ ) 


\subsection{Statistical Analysis}

a)

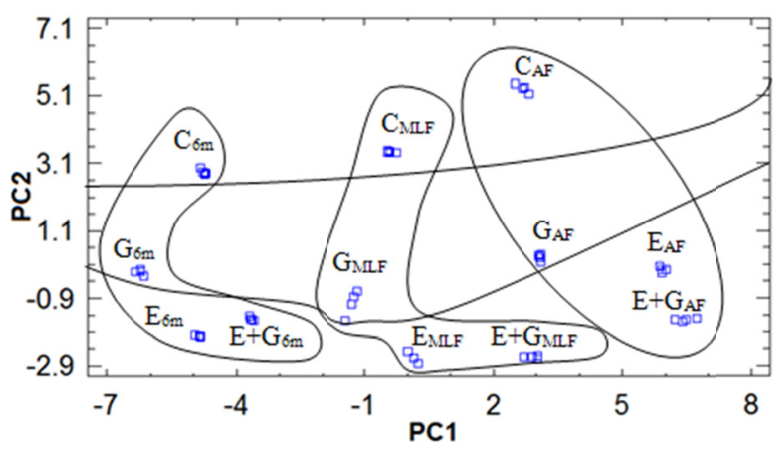

b)

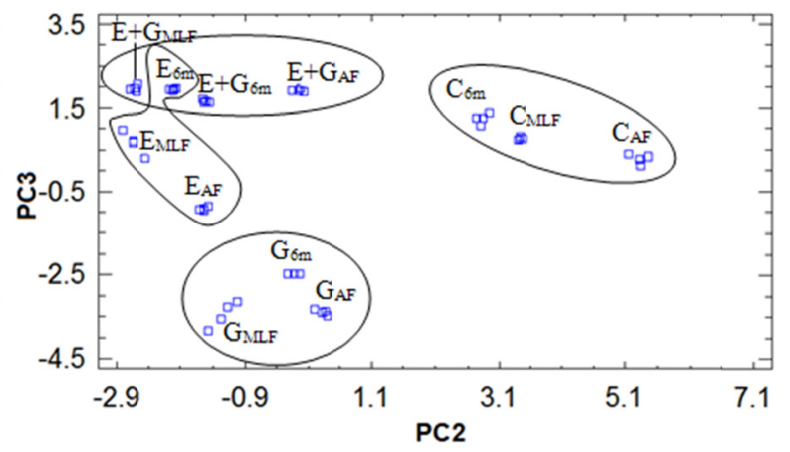

Figure 4. Principal component analysis of wine phenolic compounds. PC1: principal component 1; PC2: principal component 2; PC3: principal component 3. E: wine from grapevines eugenol treatment; G: wine from grapevines guaiacol treatment; $\mathrm{E}+\mathrm{G}$ : wine from grapevines eugenol and guaiacol treatment. $\mathrm{AF}$ : at the end of the alcoholic fermentation; MLF at the end of the malolactic fermentation; $6 \mathrm{~m}: 6$ months after malolactic fermentation

Figure $4(a, b)$ and Table 4 are the results of the principal component analysis, done with the concentration of phenolic compounds determined by HPLC-MS in the different wines studied at the different sampling times. It shows that samples from the treatments and control were separated along the first principal component (PC1), which explains $53.6 \%$ of the variance, while PC2 explains $16.2 \%$ and PC3 the $12.3 \%$. Table 4 shows each parameter weigh on the components. It can be observed that glycosides of flavonols and anthocyanins, especially the acylated, had a high weight on the PC1, which are strongly correlated with gallic acid and myricetin. On the other hand, the flavanols (+)-catechin and (-)-epicatechin, together with the stilbenes studied, syringic acid, quercetin, kaempferol and vanillic acid had the highest weight on PC2, having negative correlation, except from the last compound. We can observe that samples after 6 months are distributed on the left of PC1, while on the right are the samples after alcoholic fermentation, which had higher content of anthocyanins and flavonols. The distribution along the component 1 is according to evolution of wines. Taking into account wines from the same sampling time, we can observe that $\mathrm{E}$ and $\mathrm{E}+\mathrm{G}$ wines are located on the right of control and $\mathrm{G}$ samples, meaning the latest had lower content of anthocyanins and glycosidic flavonols than $\mathrm{E}$ and $\mathrm{E}+\mathrm{G}$ wines. The same behavior took place in the three sampling times studied, although after 6 months, $G$ wines were on the right of the others, which means that these wines lost the anthocyanins in higher degree. If remove PC1 from the plot (which are correlated with the evolution of wines over the time) and have into account PC3 versus PC2 (Figure 4(b)), samples were grouped according the treatment carried out. Variable cyanidin-3-O-glucoside, together with gallic, vanillic, syringic acids and quercetin had high weight on PC3, which were strongly correlated with $t$-resveratrol, caftaric and coutaric acids. Wines from the treatments were distributed on the left of PC2, showing they had higher content of stilbenes, (+)-catechin, (-) epicatechin, quercetin and kaempferol than control wine. On the other hand, G samples were located on the negative region of PC3, which means it had higher proportion of $t$-resveratrol than piceid, higher amount of $t$-caftaric and $t$-p-coutaric acids than samples from other treatments, which were characterized by having higher content of the variables positively correlated with PC3 (cyanidin-3-O-glucoside, gallic, vanillic, syringic acids and quercetin) (Table 4). After alcoholic fermentation, E and $\mathrm{E}+\mathrm{G}$ wines showed differences, which decreased through the sampling times. The results showed that stilbenes were the principal compounds modified by the treatments, which content increased. On the other hand, $\mathrm{G}$ wines were the samples that the least color stability presented. Maybe, the low proportion of $t$-caffeic and $t$ - $p$-coumaric in relation of their ester derivatives was related with the stability, they are in lower concentration in $\mathrm{G}$ wines, which could imply less contribution in copigmentation phenomenon. 
Table 4. Standard variables weights on the principal components

\begin{tabular}{|c|c|c|c|}
\hline & $\begin{array}{l}\text { Component } \\
1\end{array}$ & $\begin{array}{l}\text { Component } \\
2\end{array}$ & $\begin{array}{l}\text { Component } \\
3\end{array}$ \\
\hline myr-3-galac & 0,231339 & 0,055739 & 0,072551 \\
\hline myr-3-glucu & 0,233681 & 0,038484 & $-0,059826$ \\
\hline quer-3-galac & 0,218770 & 0,048992 & 0,112914 \\
\hline quer-3-glucu & 0,214291 & 0,013079 & 0,141850 \\
\hline lar-3-gluc/galac & 0,214361 & 0,12939 & 0,028584 \\
\hline syr-3-gluc & 0,160734 & 0,218631 & 0,182299 \\
\hline delf-3-gluc & 0,214901 & $-0,157769$ & 0,049011 \\
\hline cya-3-gluc & 0,115364 & $-0,163777$ & 0,247882 \\
\hline pet-3-gluc & 0,235104 & $-0,079305$ & $-0,011073$ \\
\hline peo-3-gluc & 0,196682 & $-0,167012$ & 0,172277 \\
\hline mv-3-gluc & 0,231669 & 0,011340 & $-0,046310$ \\
\hline vitisin $A$ & 0,193905 & 0,115143 & 0,100140 \\
\hline vitisin $B$ & 0,141822 & 0,188187 & $-0,17555$ \\
\hline peo-3-acetyl-gluc & 0,229452 & $-0,035911$ & 0,069057 \\
\hline mv-3-acetyl-gluc & 0,225233 & $-0,029897$ & $-0,077155$ \\
\hline mv-2-caffeoyl-gluc & 0,207637 & 0,153264 & 0,055055 \\
\hline $\begin{array}{l}\text { cyan-3-cummaroyl-glu } \\
\text { c }\end{array}$ & 0,228793 & $-0,107877$ & 0,050670 \\
\hline pet-cumaroyl-gluc & 0,228896 & $-0,087277$ & $-0,090704$ \\
\hline mv-cumaroyl-gluc & 0,230436 & $-0,062909$ & $-0,085405$ \\
\hline gallic acid & $-0,180411$ & $-0,164837$ & 0,226546 \\
\hline$(+)$-catechin & 0,088587 & $-0,352651$ & $-0,084661$ \\
\hline vanillic acid & 0,032342 & 0,217555 & 0,334758 \\
\hline caffeic acid & $-0,079018$ & $-0,15482$ & 0,159267 \\
\hline syringic acid & 0,0981307 & $-0,22434$ & 0,327048 \\
\hline (-)-epicatechin & 0,121484 & $-0,23532$ & $-0,264343$ \\
\hline coumaric acid & $-0,14358$ & $-0,157921$ & 0,171285 \\
\hline piceid-t-resveratrol & 0,080635 & $-0,347955$ & 0,081836 \\
\hline$t$-resveratrol & $-0,069542$ & $-0,221252$ & $-0,284044$ \\
\hline myricetin & $-0,205766$ & $-0,037278$ & 0,177711 \\
\hline quercetine & $-0,041538$ & $-0,243491$ & 0,248521 \\
\hline kaempferol & $-0,021817$ & $-0,377231$ & $-0,030993$ \\
\hline t-caftaric acid & 0,083671 & $-0,014153$ & $-0,248625$ \\
\hline $\mathrm{t}$-coutaric acid & 0,039697 & $-0,134289$ & $-0,331905$ \\
\hline
\end{tabular}

Myr: myricetin; quer: quercetin; lar: laricitrin; syr: syringetin; delf: delphinidin; cyan: cyanidin; pet: petunidin; peo: peonidin; mv: malvidin; galac: galactoside; glucu: glucuronide; gluc: glucoside.

\section{Conclusions}

Results have shown that the eugenol and guaiacol foliar treatments carried out to grapevines affected the wines composition and sensory characters. So, while eugenol treatment modified the concentration of phenolic secondary metabolites, guaiacol treatment produced also changes in the primary metabolism, specially sugar and acids, as well some phenolic compounds. When eugenol and guaiacol were applied altogether, a synergic effect between both compounds was observed in relation to their volatile content in wines and similar changes in color 
related compounds than in eugenol treatment were observed. Eugenol treatment stimulated the plant and enhanced the concentration of the studied compounds; increased its volatile content in wines, giving spicy notes to them and also the content of polyphenolic compounds related to color increased, as well as compounds with antioxidant and benefits properties to human health, such as stilbenes. According to the reported previously, eugenol act as a stimulant of the grape secondary metabolites which is implicated in an essential way to the compounds related to aroma, wine color stability and positive effect on health.

\section{References}

Boulton, R. (2001). The copigmentation of anthocyanins and its role in the color of red wine: A critical review. American Journal of Enology and Viticulture, 52, 67-87.

Carmona, M., Peñaranda, J. A., Carrascal, A., Zalacain, A., \& Salinas, M. R. (2001). Estudio preliminar del aumento de polifenoles y color en uva Bobal empleando extractos vegetales. Agricola Vergel, 240, 703-707.

Castillo-Muñoz, N., Gómez-Alonso, S., García-Romero, E., \& Hermosín-Gutiérrez, I. (2007). Flavonol profiles of Vitis vinifera red grapes and their single-cultivar wines. Journal of Agricultural and Food Chemistry, 55, 992-1002. http://dx.doi.org/ 10.1021/jf062800k

Castillo-Muñoz, N., González, M. F., Alonso, S. G., Romero, E. G., \& Gutiérrez, I. H. (2009). Red-color related phenolic composition of garnacha tintorera (Vitis vinifera L.) grapes and red wines. Journal of Agricultural and Food Chemistry, 57, 7883-7891. http://dx.doi.org/ 10.1021/ j99002736

Commission Regulation VO 2676/90 concerning the establishment of common analytical methods in the sector of wine, L272 (3) C.F.R. § 3 (1990). http://dx.doi.org/10.1104/pp.125.2.539

Cozzolino, D., Kwiatkowski, M. J., Parker, M., Cynkar, W. U., Dambergs, R. G., \& Gishen, M. (2004). Prediction of phenolic compounds in red wine fermentations by visible and near infrared spectroscopy. Analytica Chimica Acta, 513, 73-80. http://dx.doi.org/ 10.1016/j.aca.2003.08.066

Darias-Martín, J., Martín-Luis, B., Carrillo-López, M., Lamuela-Raventós, R., Díaz-Romero, C., \& Boulton, R. (2002). Effect of caffeic acid on the color of red wine. Journal of Agricultural and Food Chemistry, 50, 2062-2067. http://dx.doi.org/ 10.1021/jf010931+

Dixon, R. A., Lamb, C. J., Masoud, S., Sewalt, V. J. H., \& Paiva, N. L. (1996). Metabolic engineering: Prospects for crop improvement through the genetic manipulation of phenylpropanoid biosynthesis and defense responses - A review. Gene, 179, 61-71. http://dx.doi.org/ 10.1016/S0378-1119(96)00327-7

Gang, D. R., Wang, J., Dudareva, N., Nam, K. H., Simon, J. E., \& Lewinsohn, E. (2001). An investigation of the storage and biosynthesis of phenylpropenes in sweet basil. Plant Physiology, 125, 539-555. http://dx.doi.org/10.1104/pp.125.2.539

Glories, Y. (1984). La couleur des vins rouges. Les equilibres des anthocyanes et des tannins. Connaissance de la Vigne et du Vin, 18, 197-217.

Gómez-Míguez, M., González-Manzano, S., Teresa Escribano-BailóN, M., Heredia, F. J., \& Santos-Buelga, C. (2006). Influence of different phenolic copigments on the color of malvidin 3-glucoside. Journal of Agricultural and Food Chemistry, 54, 5422-5429. http://dx.doi.org/ 10.1021/jf0604586

González-Manzano, S., Dueñas, M., Rivas-Gonzalo, J. C., Escribano-Bailón, M. T., \& Santos-Buelga, C. (2009). Studies on the copigmentation between anthocyanins and flavan-3-ols and their influence in the colour expression of red wine. Food Chemistry, 114, 649-656. http://dx.doi.org/1016/j.foodchem.2008.10.002

Gunata, Y. Z., Bayonove, C. L., Baumes, R. L., \& Cordonnier, R. E. (1985). The aroma of grapes I. Extraction and determination of free and glycosidically bound fractions of some grape aroma components. Journal of Chromatography A, 331(C), 83-90. http://dx.doi.org/10.1016/0021-9673(85)80009-1

Hermosín-Gutiérrez, I., Castillo-Muñoz, N., Gomez-Alonso, S., \& García-Romero, E. (2011). Flavonol Profiles for Grape and Wine Authentication. In A. C. Society (Ed.), In Progress in Authentication of Food and Wine (pp. 113-129). Washington: Ebeler, S. http://dx.doi.org/ 10.1021/bk-2011-1081.ch008

Iriti, M., Rossoni, M., Borgo, M., \& Faoro, F. (2004). Benzothiadiazole enhances resveratrol and anthocyanin biosynthesis in grapevine, meanwhile improving resistnce to Botrytis cinerea. Journal of Agricultural and Food Chemistry, 52, 4406-4413. http://dx.doi.org/ 10.1021/jf049487b

Jeandet, P. (1997). HPLC analysis of grapevine phytoalexins coupling photodiode array detection and fluorometry. Analytical Chemistry, 69, 5172-5177. http://dx.doi.org/10.1021/ac970582b 
Kennison, K. R., Wilkinson, K. L., Pollnitz, A. P., Williams, H. G., \& Gibberd, M. R. (2009). Effect of timing and duration of grapevine exposure to smoke on the composition and sensory properties of wine. Australian Journal of Grape and Wine Research, 15, 228-237. http://dx.doi.org/ 10.1111/j.1755-0238.2009.00056.x

Lorenzo, C., Pardo, F., Zalacain, A., Alonso, G. L., \& Salinas, M. R. (2005). Effect of red grapes co-winemaking in polyphenols and color of wines. Journal of Agricultural and Food Chemistry, 53, 7609-7616. http://dx.doi.org/ 10.1021/jf050848c

Marín, J., Zalacain, A., De Miguel, C., Alonso, G. L., \& Salinas, M. R. (2005). Stir bar sorptive extraction for the determination of volatile compounds in oak-aged wines. Journal of Chromatography A, 1098, 1-6. http://dx.doi.org/ 10.1016/j.chroma.2005.07.126

Martínez-Gil, A. M., Angenieux, M., Pardo-García, A. I., Alonso, G. L., Ojeda, H., \& Rosario Salinas, M. (2013). Glycosidic aroma precursors of Syrah and Chardonnay grapes after an oak extract application to the grapevines. Food Chemistry, 138, 956-965. http://dx.doi.org/ 10.1016/j.foodchem.2012.11.032

Martínez-Gil, A. M., Garde-Cerdán, T., Martínez, L., Alonso, G. L., \& Salinas, M. R. (2011). Effect of oak extract application to Verdejo grapevines on grape and wine aroma. Journal of Agricultural and Food Chemistry, 59, 3253-3263. http://dx.doi.org/ 10.1021/jf104178c

Martínez-Gil, A. M., Garde-Cerdán, T., Zalacain, A., Pardo-García, A. I., \& Salinas, M. R. (2012). Applications of an oak extract on Petit Verdot grapevines. Influence on grape and wine volatile compounds. Food Chemistry, 132, 1836-1845. http://dx.doi.org/ 10.1016/j.foodchem.2011.12.016

Monagas, M., Bartolomé, B., \& Gómez-Cordovés, C. (2005). Evolution of polyphenols in red wines from Vitis vinifera L. during aging in the bottle: IIII. Non-anthocyanin phenolic compounds. European Food Research and Technology, 220, 331-340. http://dx.doi.org/ 10.1007/s00217-004-1109-9

Monagas, M., Martín-Álvarez, P.J., Gómez-Cordovés, C., \& Bartolomé, B. (2006). Time course of the colour of young red wines from Vitis vinifera L. during ageing in bottle. International Journal of Food Science and Technology, 41(8), 892-899. http://dx.doi.org/10.1111/j.1365-2621.2005.01132.x

Morata, A., Calderón, F., González, M. C., Gómez-Cordovés, M. C., \& Suárez, J. A. (2007). Formation of the highly stable pyranoanthocyanins (vitisins $\mathrm{A}$ and $\mathrm{B}$ ) in red wines by the addition of pyruvic acid and acetaldehyde. Food Chemistry, 100, 1144-1152. http://dx.doi.org/ 10.1016/j.foodchem.2005.11.024

Morata, A., Gómez-Cordovés, M. C., Calderón, F., \& Suárez, J. A. (2006). Effects of pH, temperature and SO2 on the formation of pyranoanthocyanins during red wine fermentation with two species of Saccharomyces. International Journal of Food Microbiology, 106, 123-129. http://dx.doi.org/ 10.1016/j.ijfoodmicro.2005.05.019

Pardo-García, A. I., Martínez-Gil, A. M., López-Córcoles, H., Zalacain, A., \& Salinas, R. (2012). Effect of eugenol and guaiacol application on tomato aroma composition determined by headspace stir bar sorptive extraction. Journal of the Science of Food and Agriculture. http://dx.doi.org/ 10.1002/jsfa.5866

Parrado, J., Escudero-Gilete, M. L., Friaza, V., García-Martínez, A., González-Miret, M. L., \& Bautista, J. D. (2007). Enzymatic vegetable extract with bioactive components: Influence of fertiliser on the colour and anthocyanins of red grapes. Journal of the Science of Food and Agriculture, 87, 2310-2318. http://dx.doi.org/ 10.1002/jsfa.2989

Peña-Neira, A., Hernández, T., García-Vallejo, C., Estrella, I., \& Suarez, J. A. (2000). A survey of phenolic compounds in Spanish wines of different geographical origin. European Food Research and Technology, 210, 445-448. http://dx.doi.org/10.1007/s002170050579

Pezet, R., Gindro, K., Viret, O., \& Spring, J. L. (2004). Glycosylation and oxidative dimerization of resveratrol are respectively associated to sensitivity and resistance of grapevine cultivars to downy mildew. Physiological and Molecular Plant Pathology, 65, 297-303. http://dx.doi.org/ 10.1016/j.pmpp.2005.03.002

Ribérau-Gayon, P., Dubourdieu, D., Donèche, B., \& Lonvaud, A. (2000). Handbook of enology, vol 1 The microbioligy of wine and vinifications. Chichester, John Wiley \& sons. Ltd.

Roldán, A., Palacios, V., Caro, I., \& Pérez, L. (2003). Resveratrol content of Palomino fino grapes: Influence of vintage and fungal infection. Journal of Agricultural and Food Chemistry, 51, 1464-1468. http://dx.doi.org/ $10.1021 / \mathrm{jf020774u}$

Rotches-Ribalta, M., Andres-Lacueva, C., Estruch, R., Escribano, E., \& Urpi-Sarda, M. (2012). Pharmacokinetics of resveratrol metabolic profile in healthy humans after moderate consumption of red 
wine and grape extract tablets. Pharmacological Research, 66, 375-382. http://dx.doi.org/ 10.1016/j.phrs.2012.08.001

Sandhu, A. K., Gray, D. J., Lu, J., \& Gu, L. (2011). Effects of exogenous abscisic acid on antioxidant capacities, anthocyanins, and flavonol contents of muscadine grape (Vitis rotundifolia) skins. Food Chemistry, 126, 982-988. http://dx.doi.org /10.1016/j.foodchem.2010.11.105

Schwarz, M., Picazo-Bacete, J. J., Winterhalter, P., \& Hermosín-Gutiérrez, I. (2005). Effect of copigments and grape cultivar on the color of red wines fermented after the addition of copigments. Journal of Agricultural and Food Chemistry, 53, 8372-8381. http://dx.doi.org/ 10.1021/jf051005o

Singh, D. P., Chong, H. H., Pitt, K. M., Cleary, M., Dokoozlian, N. K., \& Downey, M. O. (2011). Guaiacol and 4-methylguaiacol accumulate in wines made from smoke-affected fruit because of hydrolysis of their conjugates. Australian Journal of Grape and Wine Research, 17, S13-S21. http://dx.doi.org/ 10.1111/j.1755-0238.2011.00128.x

Singleton, V. L., \& Rossi, J. A., Jr. (1965). Colorimetry of total phenolics with phosphomolybdic-phosphotungstic acid reagents. American Journal of Enology and Viticulture, 16, 144-158.

Vilanova, M., Santalla, M., \& Masa, A. (2009). Environmental and genetic variation of phenolic compounds in grapes (Vitis vinifera) from northwest Spain. Journal of Agricultural Science, 147, 683-697. http://dx.doi.org/10.1017/s0021859609990141

Winterhalter, P., \& Skouroumounis, G. K. (1997). Glycoconjugated aroma compounds: occurrence, role and biotechnological transformation. Advances in biochemical engineering/biotechnology, 55, 73-105. http://dx.doi.org/10.1007/BFb0102063

Zafrilla, P., Morillas, J., Mulero, J., Cayuela, J. M., Martínez-Cachá, A., \& Pardo, F. (2003). Changes during storage in conventional and ecological wine: Phenolic content and antioxidant activity. Journal of Agricultural and Food Chemistry, 51, 4694-4700. http://dx.doi.org/ 10.1021/jf021251p

\section{Copyrights}

Copyright for this article is retained by the author(s), with first publication rights granted to the journal.

This is an open-access article distributed under the terms and conditions of the Creative Commons Attribution license (http://creativecommons.org/licenses/by/3.0/). 